\title{
BATHYMETRY MAPPING USING HYPERSPECTRAL DATA: A CASE STUDY OF YAMADA BAY, NORTHEAST JAPAN
}

\author{
E. Ariyasu ${ }^{\text {a, } *, \text { S. Kakuta }}{ }^{\text {a }}$, and T. Takeda ${ }^{\text {b }}$ \\ a Asia Air Survey Co., Ltd., 1-2-2 Manpukuji, Asao, Kawasaki, Kanagawa 215-0004 Japan - (emk.ariyasu, stm.kakuta)@ ajiko.co.jp \\ b Japan Space Systems, 3-5-8 Shibakoen, Minato-ku, Tokyo 105-0011 Japan - Takeda-Tomomi@ jspacesystems.or.jp
}

Commission VII, WG VII/3

KEY WORDS: CASI-1500h, inversion method, semi-analytical model, simulation, seagrass meadow, shallow water

\begin{abstract}
:
This study aims to examine if the inversion method using hyperspectral data is applicable in Japan. Nowadays, overseas researchers are mainly applied an inversion method for accurately estimating water depth. It is able to gain not only water depth, but also benthic spectral reflection and inherent optical properties (IOPs) at the same time, based on physics-based radiative transfer theory for hyperspectral data. It is highly significant to understand the possibility to develop the application in future for coastal zone of main island, which is a common water quality in Japan, but there is not any case study applied this method in Japan. The study site of Yamada bay in Iwate Prefecture is located in northeast of Japan. An existed analytical model was optimized for mapping water depth in Yamada bay using airborne hyperspectral image and ground survey data which were simultaneously acquired in December, 2015. The retrieved remote-sensing reflectance $\left(\mathrm{R}_{\mathrm{rs}}\right)$ is basically qualitatively appropriate result. However, when compared with all ground survey points, the retrieved water depth showed low correlation, even though ground points which are selected sand bottom indicates high relationship. Overall, we could understand the inversion method is applicable in Japan. However, it needs to challenge to improve solving error-caused problems.
\end{abstract}

\section{INTRODUCTION}

Bathymetric features are often changed over time from the water movement. Accurate shallow-water bathymetry is significant to acquire for costal management, such as safe navigation, but also necessary for disaster science for flood and tsunami simulation. For example, when the Great East Japan earthquake triggered devastative tsunami in northeast Japan on March 11, 2011, the feature of sea bottom were extremely changed by huge amount of large debris and big water energy movement. When changed, the latest technology in bathymetry, it is measurable in spatial and accurate by a narrow multi beam and airborne lidar bathymetry (ALB). However, the cost performance is high, so that it is not possible to widely measure. So, it is getting popular to use satellite-derived bathymetry in the aspect of cost performance and wide acquisition, even though the accuracy is, of course, declined than the above technologies. The satellitederived bathymetry is meant to be mostly multi-spectral satellite data, which is required a ground survey and limited only applied in homogeneous water quality and bottom type. On the other hand, hyperspectral data is able to gain not only water depth, but also benthic spectral reflection and inherent optical properties (IOPs) at the same time, based on spectral reflection and radiative transfer theory by hyperspectral data.

This original study is a part of the "Research and Development Project for the Next-generation Earth Observation Satellite Utilization Technology" conducted by Japan Space Systems entrusted by Ministry of Economy, Trade and Industry (METI). The goal is to apply for developing application for using hyperspectral data in coastal fields.

Bathymetry using hyperspectral data is approached from physicsbased radiative transfer model. A shallow water semi-analytical model, called Hyper-spectral Optimization Process Exemplar
(HOPE), was developed by Lee et al $(1989,1999)$. Inversion of physics-based radiative transfer model is globally applied in coastal remote sensing in overseas. However, there is not any case study applied in Japan yet. Thus, this study is examined the inversion method is applicable at Yamada Bay, Iwate prefecture, Japan.

\section{MATERIALS}

\subsection{Study site}

The study site in Yamada bay, Iwate prefecture is located in northeast of main island, Japan $\left(39.45^{\circ} \mathrm{E}, 141.97^{\circ} \mathrm{W}\right)$ (Figure 1). The climate is cold and temperate which indicated Dfb in the Koppen-Geiger climate classification. The average annual temperature is $11.5 \mathrm{C}^{\circ}$ and the average monthly temperature in December, 2015 is $4.2 \mathrm{C}^{\circ}$, according to Japan Metrological Agency. Also, the annual rainfall is $1327.5 \mathrm{~mm}$ in 2015. Yamada bay is a ria coast. The inner part of bay is widely distributed with sand bottom and the wave is calm, so which are meant to be an appropriate environment for growing seagrass. Also, rocked-area is grown by annual and perennial brown macroalgae. The water quality is not different with the other bay of northeast Japan.

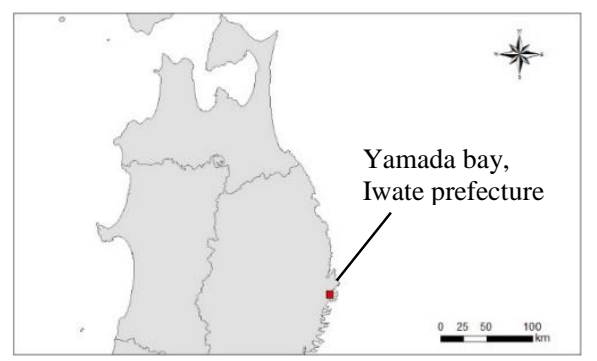

Figure 1. Location of the study area

\footnotetext{
* Corresponding author
} 


\subsection{Airborne hyperspectral data}

The hyperspectral data was acquired with a sensor, CASI-1500h in December 7, 2015. The flight direction was from north to south and the courses were composed of three courses from left $(\mathrm{C} 1)$ to right (C3). The sensor produced by Itres has 144 spectral bands over the wavelength range from 367 to $1,047 \mathrm{~nm}$. The flight altitude was approximately $3,000 \mathrm{~m}$ and resulted in a ground resolution of $1.5 \mathrm{~m}$ with $4.75 \mathrm{~nm}$ of spectral resolution. The climate condition is fine weather and the average wind speed in the flight duration is $0.7 \mathrm{~m} / \mathrm{s}$ (JMA, 2016).

\subsection{Field measurements}

The Yamada bay was surveyed 59 points in December 9 th- $10^{\text {th }}$, 2015. The survey was collected geospatial location by Garmin eTrex20J and identified benthic type and cover ratio by specialist. Also, chlorophyll-a concentration and water depth were measured by RINKO-Profiler ASTD101 of JFE Advantech Co., Ltd. In the same time, dominant benthic types were measured spectral reflectance by ASD (Analytical Spectral Devices) FiledSpec3, which ranges from 350 to $2500 \mathrm{~nm}$ with an interval of $3 \mathrm{~nm}$. The spectrometer was perpendicularly measured at a water tank on the ground in higher elevation angle, avoiding the clouds.

In this field survey, the total benthic types collected in the field survey 18 types mainly distributed (seagrass and seaweeds, sands, grabble, and rock.), and the dominant types were seagrass of Zosteraceae family (e.g., Zostera marina), brown macroalga (e.g. Sargassum micracanthum), and red macroalga (e.g., Symphyocladia linearis), and the cover ratios are variable. Also, the season for this study was seagrass and macroalga were brownish for declining season. The survey was investigated from $1 \mathrm{~m}$ to $20 \mathrm{~m}$ of water depth, and the chlorophyll-a concentration was from 0.3 to $1.15 \mu \mathrm{g} / \mathrm{L}$.

\section{METHODS}

\subsection{Pre-processing}

The original hyperspectral data was processed geometrical correction based on IMU mounted in aircraft and then rectified as an orthotification by using $5 \mathrm{~m}$ DEM released by Geospatial Information Authority of Japan. After the process, data converted into radiometric resolution was provided with $1.5 \mathrm{~m}$ of ground resolution for this study. The data was applied an atmospheric correction with Fast Line-of-Sight Atmospheric Analysis of Spectral Hypercube (FLAASH), which is a MODTRAN-4 based approach that is available in ENVI software. The atmospheric model was applied with Mid-Latitude Winter, and the aerosol model was selected Maritime. Also, water retrieval is applied with $950 \mathrm{~nm}$ of water absorption feature. As a result, values of relative reflectance include negative values, and added 0.01 not to be negative values in the spectral range from 400 to $800 \mathrm{~nm}$.

\subsection{Inversion method}

Inversion method by Lee et al. in 1998 and 1999 is defined remote sensing reflectance $\mathrm{R}_{\mathrm{rs}}$, as below;

$$
\begin{aligned}
& \mathrm{R}_{\mathrm{rs}} \approx \frac{0.5 \mathrm{r}_{\mathrm{rs}}}{1-1.5 \mathrm{r}_{\mathrm{rs}}} \\
& \mathrm{r}_{\mathrm{rs}} \approx \mathrm{r}_{\mathrm{rs}}^{\mathrm{dp}}\left[1-\exp \left(-\left(\frac{1}{\cos \theta_{\mathrm{w}}}+\frac{\mathrm{D}_{\mathrm{u}}^{\mathrm{C}}}{\cos \theta_{\mathrm{v}}}\right) \kappa \mathrm{H}\right)\right]+ \\
& \frac{1}{\pi} \rho \exp \left(-\left(\frac{1}{\cos \theta_{\mathrm{w}}}+\frac{\mathrm{D}_{\mathrm{u}}^{\mathrm{B}}}{\cos \theta_{\mathrm{v}}}\right) \kappa \mathrm{H}\right) \\
& \mathrm{r}_{\mathrm{rs}}^{\mathrm{dp}} \approx(0.084+0.170 \mathrm{u}) \mathrm{u}
\end{aligned}
$$

$$
\begin{aligned}
& \mathrm{D}_{\mathrm{u}}^{\mathrm{C}} \approx 1.03(1+2.4 \mathrm{u})^{0.5}, \mathrm{D}_{\mathrm{u}}^{\mathrm{B}} \approx 1.04(1+5.4 \mathrm{u})^{0.5} \\
& \mathrm{u}=\mathrm{b}_{\mathrm{b}} /\left(\mathrm{a}+\mathrm{b}_{\mathrm{b}}\right), \kappa=\mathrm{a}+\mathrm{b}_{\mathrm{b}} \\
& \mathrm{b}_{\mathrm{b}}=\mathrm{b}_{\mathrm{bw}}+\mathrm{b}_{\mathrm{bp}}, \mathrm{a}=\mathrm{a}_{\mathrm{w}}+\mathrm{a}_{\phi}+\mathrm{a}_{\mathrm{g}}
\end{aligned}
$$

where $r_{r s}$ is the subsurface remote sensing refrectance, $r_{r s}^{d p}$ is the remote sensing reflectance for optically deep waters $\left(\mathrm{sr}^{-1}\right), \mathrm{D}_{\mathbf{u}}^{\mathbf{C}}$ is the photon from the water column $\left(\mathrm{sr}^{-1}\right), \theta_{\mathrm{w}}$ is the subsurface solar zenith angle (rad), $\theta_{\mathrm{v}}$ is the subsurface viewing angle from nadir ( $\mathrm{rad}), \mathrm{H}$ is the depth of bottom $(\mathrm{m}), \mathrm{u}$ and $\mathrm{\kappa}$ is the inherent optical properties, $a$ is the total absorption coefficient, $\mathrm{a}_{\mathrm{w}}$ is the absorption coefficient of pure water $\left(\mathrm{m}^{-1}\right), \mathrm{a}_{\phi}$ is the absorption coefficient of phytoplankton pigments $\left(\mathrm{m}^{-1}\right), \mathrm{a}_{\mathrm{g}}$ is the absorption coefficient of gelbstoff $\left(\mathrm{m}^{-1}\right), b_{b}$ is the total backscattering coefficients $\left(\mathrm{m}^{-1}\right), \mathrm{b}_{\mathrm{bw}}$ is the backscattering coefficients of pure water $\left(\mathrm{m}^{-1}\right), \mathrm{b}_{\mathrm{bp}}$ is the backscattering coefficients of suspended particles $\left(\mathrm{m}^{-1}\right)$. The parameters of $b_{b w}$ and $a_{w}$ are known by Pope and Fry (1997) and Morel (1974).

The models of $\mathrm{a}_{\varphi}, \mathrm{a}_{\mathrm{g}}, \mathrm{b}_{\mathrm{bp}}$, and $\rho$ are defined with single-parameter as below.

$$
\begin{aligned}
& a_{\phi}(\lambda)=\left[a_{0}(\lambda)+a_{1}(\lambda) \ln (P)\right] P \\
& a_{g}(\lambda)=G e^{-0.015(\lambda-440)} \\
& b_{b p}(\lambda)=X\left(\frac{550}{\lambda}\right)^{0.5}
\end{aligned}
$$

where $\mathrm{P}$ is $a_{\phi}(440)$, the variable for phytoplankton absorption coefficient at $440 \mathrm{~nm}, \mathrm{G}$ is $a_{g}(440), \mathrm{X}$ is $\mathrm{b}_{\mathrm{bp}}(550)$. $\mathrm{a}_{0}(\lambda), \mathrm{a}_{1}(\lambda)$ are given by Lee et al. (1998).

The parameter $\rho(\lambda)$ is expressed using $550 \mathrm{~nm}$-normalized sand albedo $\rho_{\text {sand }}(\lambda)$ or grass albedo $\rho_{\text {grass }}(\lambda)$ shapes

$$
\rho(\lambda)=\mathrm{B} \rho_{\text {sand }}(\lambda) \text { or } \rho(\lambda)=\mathrm{B} \rho_{\text {grass }}(\lambda)
$$

where $\mathrm{B}$ is the bottom albedo value at $550 \mathrm{~nm}$.

We used the following empirical criteria to initially separate sand from grass bottoms: if $\mathrm{R}_{\mathrm{rs}}(\lambda)$ of a pixel satisfies;

$$
R_{r s}^{\text {meas }}(550)<0.03 \text { and } R_{r s}^{\text {meas }}(710) / R_{r s}^{\text {meas }}(670)<0.4 \text {, }
$$

spectral shape of $\rho_{\text {grass }}$ is used; otherwise, spectral shape of psand is used.

In the simulation process, values of [chl-a], $\mathrm{P}, \mathrm{G}, \mathrm{X}, \mathrm{B}$, and $\mathrm{H}$ are initiated pixel-use, and the $\mathrm{P}$ and $\mathrm{X}$ are referred a model from Gordon and Morel (1993).

$$
\begin{aligned}
& {[c h l-a]=0.3} \\
& \mathrm{P}=0.06[\text { chl }-a]^{0.65} \\
& \mathrm{G}=\mathrm{P} \\
& \mathrm{X}=0.03[\text { chl }-a]^{0.62} \\
& B=\rho_{\text {sand }}(550) \text { or } \rho(550)=\rho_{\text {sand }}(550) \\
& H=1
\end{aligned}
$$

Error function defined by $R_{r s}$ and $R_{r s}^{\text {meas }}$ in the below formula to get minimized.

$$
\operatorname{err}=\frac{\left[\sum_{450}^{675}\left(R_{r s}^{\text {meas }}-\mathrm{R}_{\mathrm{rs}}\right)^{2}+\sum_{750}^{800}\left(R_{r s}^{\text {meas }}-\mathrm{R}_{\mathrm{rs}}\right)^{2}\right]^{0.5}}{\sum_{450}^{675} R_{r s}^{\text {meas }}+\sum_{750}^{800} R_{r s}^{\text {meas }}}
$$




\section{RESULTS}

\subsection{Bathymetric map}

Figure 2 to Figure 5 show the retrieved $R_{\mathrm{rs}}$ (straight line) compared with $R_{r s}^{\text {meas }}$ (dot line) at sand at Figure 2 to Figure 3 and seaweed target at Figure 4 to Figure 5. Before comparing the retrieved result, the ground data were corrected to adjust the tidal level with the acquisition of the hyperspectral data.

Figure 2 indicates $\mathrm{R}_{\mathrm{rs}}$ of sand target at $1.03 \mathrm{~m}$ water depth. The parameters of the variables for simulation are defined as [chl-a] in $0.8, \mathrm{P}$ in $0.06, \mathrm{X}$ in 0.08 , and $\mathrm{H}$ in 1.0 .

Figure 3 indicates the $\mathrm{R}_{\mathrm{rs}}$ of sand target at $2.03 \mathrm{~m}$ water depth. The parameters of the variables are defined as [chl-a] in $0.8, \mathrm{P}$ in $0.06, \mathrm{X}$ in 0.61 , and $\mathrm{H}$ in 1.5 .

The patterns of retrieved water depth in both figures are matched with the hyperspectral data well, except the spectral reflectance in hyperspectral data is under $450 \mathrm{~nm}$ and over $750 \mathrm{~nm}$. The chlorophyll-a concentration was proper values with the ground data. Also, those both figures easily showed the shape and trend are changed by different water depth.

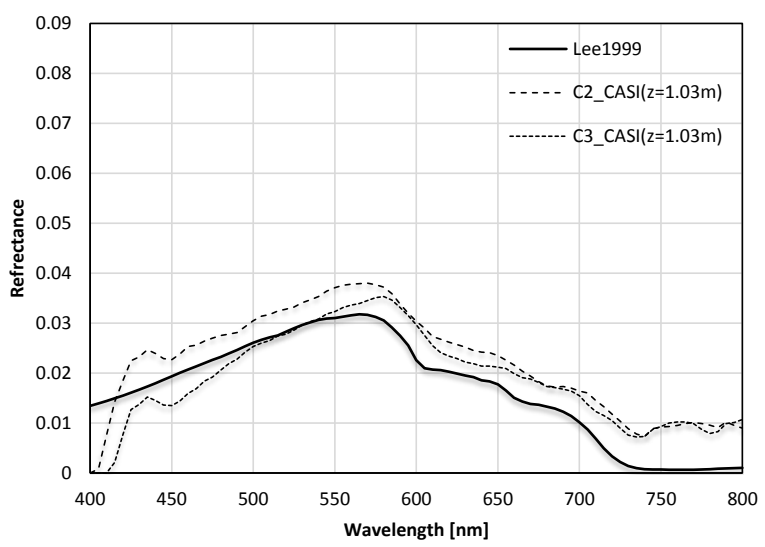

Figure 2. Sand spectral simulation at $1.03 \mathrm{~m}$ water depth

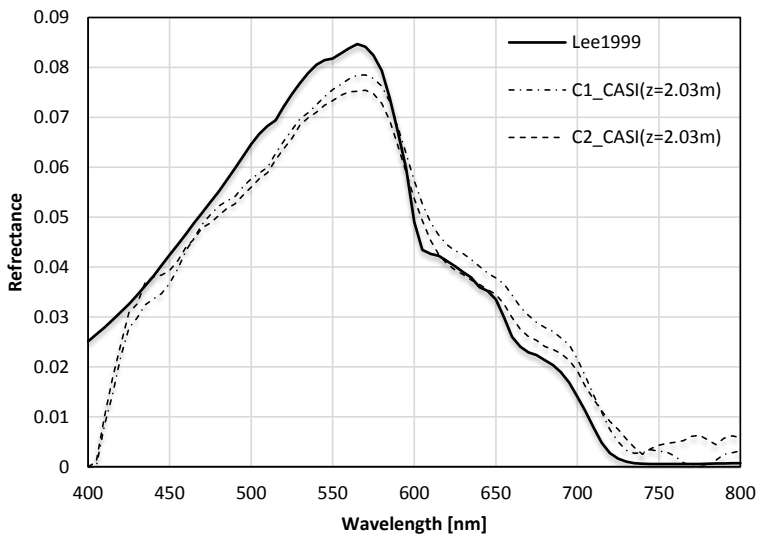

Figure 3. Sand spectral simulation at $2.03 \mathrm{~m}$ water depth

Figure 4 indicates $\mathrm{R}_{\mathrm{rs}}$ of seagrass target at $1.53 \mathrm{~m}$ water depth. The parameters of the variables are defined as [chl-a] in $0.8, \mathrm{P}$ in $0.06, \mathrm{X}$ in 0.08 , and $\mathrm{H}$ in 1.0 .
Figure 5 indicates $\mathrm{R}_{\mathrm{rs}}$ of seagrass target at $2.23 \mathrm{~m}$ water depth. The parameters of the variables are defined as [chl-a] in $0.8, \mathrm{P}$ in $0.06, \mathrm{X}$ in 0.27 , and $\mathrm{H}$ in 2.5 .

The simulation both depths were well matched. However, in contrast to sand bottom, the figure 4 and 5 show very similar spectral ranges and shape of spectral reflectance. The retrieved depth is also same, and could not show the difference in depth.

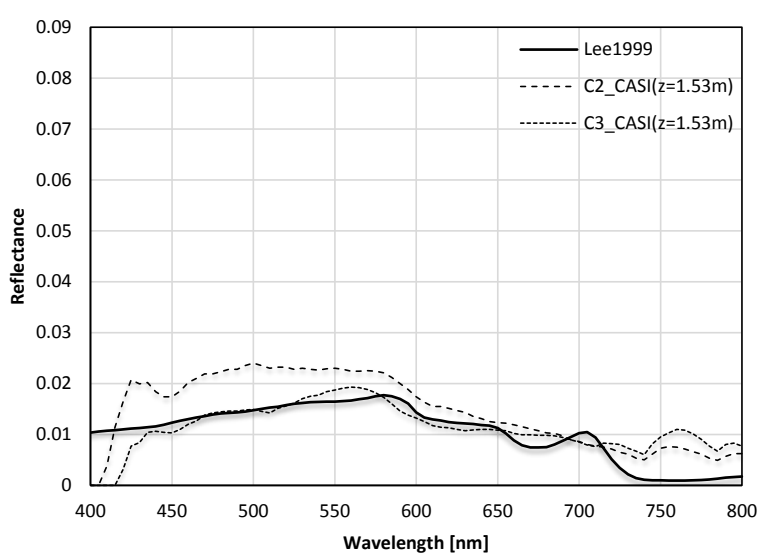

Figure 4. Seagrass spectral simulation at $1.53 \mathrm{~m}$ water depth

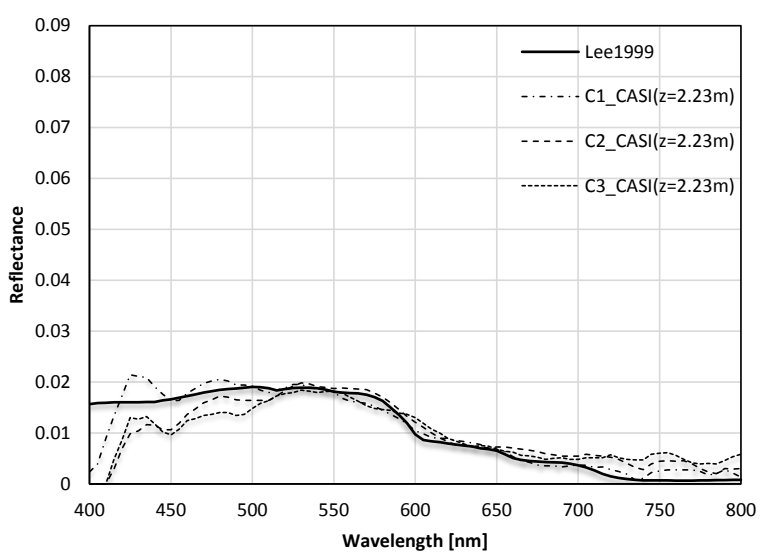

Figure 5. Seagrass spectral simulation at $2.23 \mathrm{~m}$ water depth

\subsection{Assessment}

The retrieved depth was compared the reliability with ground survey data. Figure 6 shows a scatter plot with all ground survey data. The slope is 0.467 and the intercept is 2.182 . Also, the coefficient of determination is 0.196 , which is extremely low.

Figure 7 plots only a sand target of the all ground survey points. The slope is 0.610 and the intercept is 1.502 . The coefficient of determination is 0.700 , which is dramatically better than all mixed targets. That is, the sand target indicates a relationship with the simulation, but the other targets like seagrass does not have correlative correlation. 


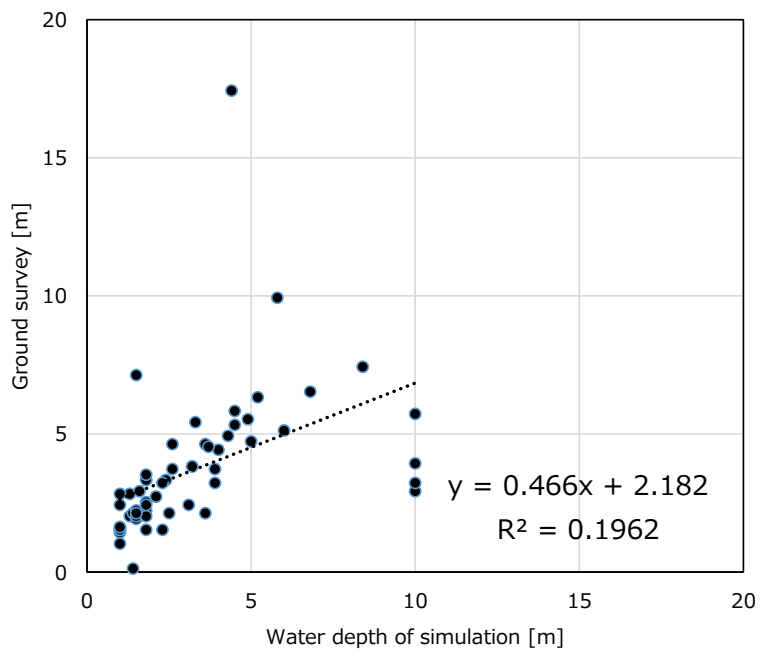

Figure 6. Comparison with ground truth

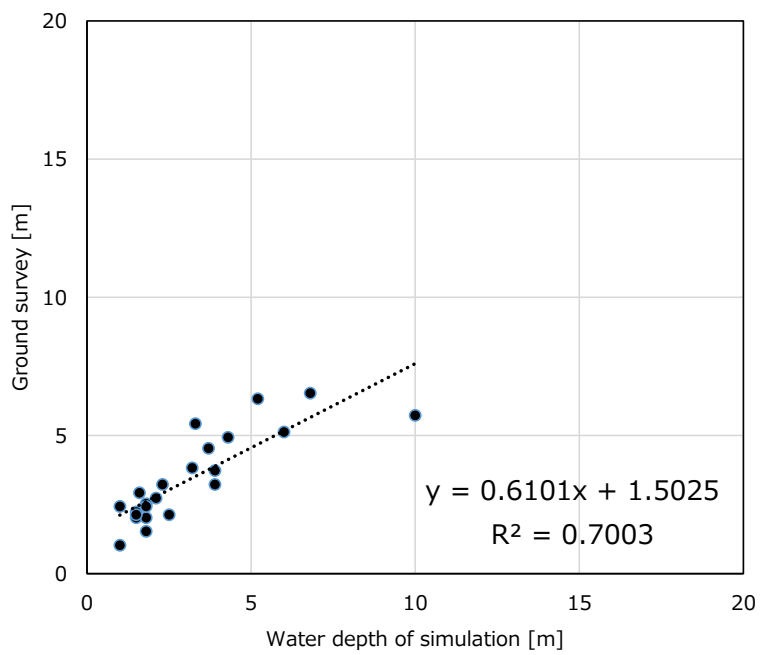

Figure 7. Comparison with ground truth (sand)

\section{DISCUSSION}

We could examine the inversion method is applicable in Japan. The trend of retrieved reflectance was qualitatively matched well. However, as looked at the assessment with all benthic types of ground survey points was low correlation. The reason caused for low correlation with ground data will be considered that grass albedo $\rho_{\text {grass }}(\lambda)$ was not only detected seagrass. Ground survey indicated variable bottom types, such as rubbles and microalga. However, the simulation model is not considered the variable bottom types. Also, the other reason is that the seagrass cover ratio in the ground survey is different from 30 to 100 percentage. The study area was abundant benthic types, which will cause the low correlation. In the aspect of remote sensing, the spatial resolution is not fully covered with a target, which cause a mixed pixel from the other targets. The mixed pixel may include sand, seagrass, and macroalga. For resolving the problems, we need to improve the model, considering different bottom type and mixed pixel, such as BRUCE (Klonowski et al., 2001) and SANBUKA (Brando et al, 2003).

\section{CONCLUSION}

This study investigated to map water depth with hyperspectral data by using inversion method leading from semi-analytical model developed by Lee et al. (1998, 1999). Ground survey was simultaneously investigated with the acquisition of hyperspectral data to understand the benthic types and cover ratio, water depth and chlorophyll-a concentration, and in-situ spectral reflectance of main benthic types. Using the ground survey data, we simulated $\mathrm{R}_{\mathrm{rs}}$ based on the inversion method and retrieved water depth. We assessed the result by using data of ground survey. The retrieved depth shows low interrelationship with every data taken in ground survey, but the result show high correlation as the assessment points are selected in only sand target. The reason may be caused of the bay distributed with abundant bottom types. In the next study for solving the problem, we need to challenge to improve the accuracy of seaweed bottom and try the different model considering different bottom types.

\section{ACKNOWLEDGEMENTS}

We greatly thank to Dr. Hiroya Yamano, National Institute for Environmental Studies, gave us technical advice for collecting in-situ spectral reflectance data.

\section{REFERENCES}

Brando, V. E., and A. G. Dekker. 2003. Satellite hyperspectral remote sensing for estimating estuarine and coastal water quality. IEEE Transion on Geoscice and Remote Sensing. 41:1378-1387

Gordon H.R. and Morel A., Remote Assissment of Ocean color for Interpretation of Satellite Visible Imagery: A review., Spronger-Verlag, New York, 1983, p. 44.

Japan Metrological Agency. 2015. Past atmospheric data search, Data and document, Monthly and Annual record of Miyako bay, Iwate, Japan. http://www.data.jma.go.jp/obd/stats/etrn/index.p hp?prec_no $=33 \&$ block $\_$no $=1033 \&$ year $=2015 \&$ month $=\&$ day $=\&$ view=p1 (25 March, 2016)

Klonowski, W. M., P. R. C. S. Fearns, and M. J. Lynch. 2007. Retrieving key benthic cover types and bathymetry from hyperspectral imagery. Journal of Application Remote Sensing. 1:011505

Lee, Z.P., Carder, K.L., Mobley, C.D., Steward, R.G. and Patch, J.S., 1999, Hyperspectral remote sensing for shallow waters 2. Deriving bottom depths and water properties by optimization, Applied Optics, vol. 38, no. 18, p. 3831-3843.

Lee, Z.P., Carder, K.L., Chen, R.F., and Peacock, T.G., 2001, Properties of the water column and bottom derived from Airborne Visible Infrared Imaging Spectrometer (AVIRIS) data, Journal of Geophysical Research, vol. 116, no. C6, p. 1163911651.

Morel, A. 1974. Optical properties of pure water and pure sea water, p. 1-24. In N. G. Jerlov and E. S. Nielsen [eds.], Optical Aspects of Oceanography. Academic Press.

Pope, R. M., and E. S. Fry. 1997. Absorption spectrum (380-700 $\mathrm{nm}$ ) of pure water. II. Integrating cavity measurements. Applied Optic. 36:8710-8723 